\title{
Análise integrada da paisagem na bacia hidrográfica de Coronel João Pessoa/RN
}

A análise de uma paisagem a partir de uma bacia hidrográfica possui a vantagem de deter limites bem definidos, onde o modelo e formato da bacia definem os arranjos da paisagem, o que reflete os efeitos de forma óbvia decorrentes das atividades antrópicas na área. O objetivo do trabalho foi realizar uma análise integrada da paisagem por meio de recursos das geotecnologias ao considerar aspectos físicos e ambientais da Bacia Hidrográfica de Coronel João Pessoa/RN. Para o desenvolvimento da pesquisa e compreensão da diversidade e complexidade da paisagem, elaborou-se cartas temáticas para caracterização de atributos físicos e ambientais da unidade territorial. Foram identificadas as APP's no qual foram classificadas como as encostas de declividade acima de $45 \%$, reservatórios em zona rural, nascentes e rede de drenagem, onde, o uso do solo nessas áreas para fins de agricultura, pastagem, instalação de edifícios com rede de esgoto, tem alertado para possíveis fragilidades ambientais nessas áreas. A análise integrada multitemporal da paisagem entre 2009 e 2019 , mostra uma expansão da vegetação nativa e um aumento significativo das águas superficiais, apesar da diminuição de precipitações pluviométricas. Verificou-se uma diminuição das ações antrópicas, que não foi o suficiente para reduzir a área de solo exposto, assim como a presença de afloramento rochoso ao longo da superfície terrestre da bacia. Em relação a cobertura vegetal, está sofreu uma redução em áreas com declividade acima de $45 \%$, logo, é possível inferir que houve crescente desmatamento da área devido, principalmente, as atividades antrópicas recorrentes nestas áreas, como a agricultura.

Palavras-chave: Aspectos Físicos e Ambientais; Semiárido; Uso e Ocupação do Solo; Geotecnologias.

\section{Integrated analysis of the landscape in the hydrographic basin Coronel João Pessoa/RN}

\begin{abstract}
An analysis of a landscape from a river basin has the advantage of determining well-defined boundaries, where the model and shape of the basin define the landscape arrangements, or the effects that obviously affect anthropic activities in the area. The objective of the work was to carry out an integrated analysis of the landscape using geotechnological resources when considering physical and environmental aspects of the Hydrographic Basin Coronel João Pessoa/RN. For the development of research and understanding of the diversity and complexity of the landscape, thematic charts were drawn up to characterize the physical and environmental attributes of the territorial unit. APPs were identified in which they were classified as slopes above $45 \%$, reservoirs in rural areas, springs and drainage network, where the use of the soil in these areas for purposes of agriculture, pasture, installation of buildings with sewage, has warned of possible environmental weaknesses in these areas. The integrated multitemporal analysis of the landscape between 2009 and 2019 , shows an expansion of native vegetation and a significant increase in surface waters, despite the decrease in rainfall. There was a decrease in anthropic actions, which was not enough to reduce the area of exposed soil, as well as the presence of rocky outcrops along the terrestrial surface of the basin. In relation to vegetation cover, this has been reduced in areas with a slope above $45 \%$, so it is possible to infer that there was increasing deforestation in the area, mainly due to the recurrent human activities in these areas, such as agriculture.
\end{abstract}

Keywords: Physical and Environmental Aspects; Semiarid; Land Use and Occupation; Geotechnologies.

Topic: Engenharia Ambiental

Reviewed anonymously in the process of blind peer.
Received: 01/12/2020

Approved: $23 / 12 / 2020$
Alana Ticiane Alves do Rêgo (iD)

Universidade do Estado do Rio Grande do Norte, Brasil http://lattes.cnpq.br/6783254406806614 http://orcid.org/0000-0001-9005-2610 alana_ticiane10@hotmail.com

Helves Cleverton Guerra Costa (10) Universidade Federal Rural do Semiárido, Brasil http://lattes.cnpq.br/9052627585320406 http://orcid.org/0000-0002-4895-6840 helves.guerra5@gmail.com

\section{Samilly Brito Nobre (iD)}

Universidade Federal Rural do Semiárido, Brasil http://lattes.cnpq.br/5874088040659404 http://orcid.org/0000-0001-9915-1818 samillybritto2010@hotmail.com

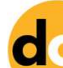

DOI: 10.6008/CBPC2179-6858.2020.007.0027
Rafael Silva de Souza (D)

Universidade do Estado do Rio Grande do Norte, Brasil http://lattes.cnpq.br/5061185846392673 http://orcid.org/0000-0001-8689-8189 rafael2100cruzada@hotmail.com

Antônio Batista de Queiroz Júnior (D) Universidade Federal Rural do Semiárido, Brasil http://lattes.cnpq.br/6882297538884280 http://orcid.org/0000-0003-3911-3881 antonio.queiroz17@gmail.com

\section{Ricassilly Isac Bruno Rufino Lima (iD)}

Universidade Federal Rural do Semiárido, Brasil http://lattes.cnpq.br/1677458778246978 http://orcid.org/0000-0002-6096-4827

ricassilly@hotmail.com
Talita Tássia da Costa (D)

Universidade Federal Rural do Semiárido, Brasil http://lattes.cnpq.br/0751541426540864 http://orcid.org/0000-0001-6912-8932 talitatcosta@hotmail.com

Francisco Soares Roque (it)

Universidade Federal Rural do Semiárido, Brasi http://lattes.cnpq.br/4466838919204802 http://orcid.org/0000-0003-3524-2344 fabiokand@gmail.com

\section{Joel Medeiros Bezerra (iD}

Universidade Federal Rural do Semiárido, Brasil http://lattes.cnpq.br/6945041178312614 http://orcid.org/0000-0002-8150-4125

joel.medeiros@ufersa.edu.br

Referencing this:

RÊGO, A. T. A.; COSTA, H. C. G.; NOBRE, S. B.; SOUZA, R. S.; QUEIROZ JÚNIOR, A. B.; LIMA, R. I. B. R.; COSTA, T. T.; ROQUE, F. S.; BEZERRA, J. M.. Análise integrada da paisagem na bacia hidrográfica de Coronel João Pessoa/RN. Revista Ibero Americana de Ciências Ambientais, v.11, n.7, p.321-337, 2020. DOI: http://doi.org/10.6008/CBPC21796858.2020 .007 .0027 


\section{INTRODUÇÃO}

Os processos de materialização dos sistemas ambientais que atuam criando e recriando contornos na natureza e que são visualizados por nós, constituem a paisagem, no qual é uma visão rudimentar antes mesmo do conhecimento de sua definição, que se delimita no corpo terrestre criando arranjos, onde as condições naturais peculiares de localização irão condicionar o arranjo morfológico, definindo a paisagem analisada (ALEXANDRE et al., 2019).

A análise de uma paisagem a partir de uma bacia hidrográfica possui a vantagem de deter limites bem definidos, onde o modelo e formato da bacia definem os arranjos da paisagem, o que reflete os efeitos de forma óbvia decorrentes das atividades antrópicas na área, como a fragmentação da sua cobertura vegetal e a intensificação de processos erosivos (MOREIRA et al., 2015; VALE et al., 2015).

Nesse aspecto, a maior preocupação está na ocupação indevida dessas bacias (EUGENIO et al., 2017). Em grande parte, essas ocupações ocorrem sem planejamento ou enquadramento legal e, por muitas vezes, culminando na ausência de saneamento básico, além de problemas relacionados as enchentes sem precedentes (SOARES, 2018). Com isso, a degradação de áreas prioritárias e vulneráveis se torna inerente.

Diante desse contexto de análise integrativa da paisagem e compreensão de elementos que compõem e interferem na dinâmica de uma bacia hidrográfica, alguns autores têm adotado as geotecnologias para mapeamento da paisagem e realização de estudos para interpretações úteis ao planejamento da área, como Lucena et al. (2014), Azevedo et al. (2016) e Silva et al. (2016).

A bacia hidrográfica de Coronel João Pessoa/RN possui uma grande importância regional e destacase por ser uma fonte de abastecimento da cidade. No entanto, as condições naturais de estiagem e a falta de gestão de seus recursos hídricos comprometem a disponibilidade em quantidade e qualidade para seus usos múltiplos, resultando em uma mudança gradual significativa da paisagem. Além disso, a expansão não planejada e o crescente número de ações antrópicas em seu entorno, principalmente de atividades decorrentes da agropecuária, potencializam os riscos de contaminação em todos os compartimentos ambientais, corroborando para a necessidade de compreensão de elementos físicos e ambientais integrados a essa unidade territorial.

Nesse sentido, diante da importância de levantar informações acerca dessa unidade territorial e servir de subsídio para o planejamento e conservação dos recursos naturais da região, o presente trabalho teve como objetivo realizar uma análise integrada da paisagem por meio de recursos das geotecnologias ao considerar aspectos físicos e ambientais da Bacia Hidrográfica de Coronel João Pessoa/RN.

\section{MATERIAIS E MÉTODOS}

\section{Delimitação e caracterização da área de estudo}

A área de estudo corresponde a Bacia Hidrográfica de Coronel João Pessoa (BHCJP), localizada predominantemente no município de Coronel João Pessoa no Rio Grande do Norte, e que possui seu exutório localizado no Açude Público Municipal da Vila Caldeirão do município em questão. Ainda contempla uma 
pequena porção de outros municípios do RN, e o município de Poço Dantas no estado da Paraíba (Figura 1).

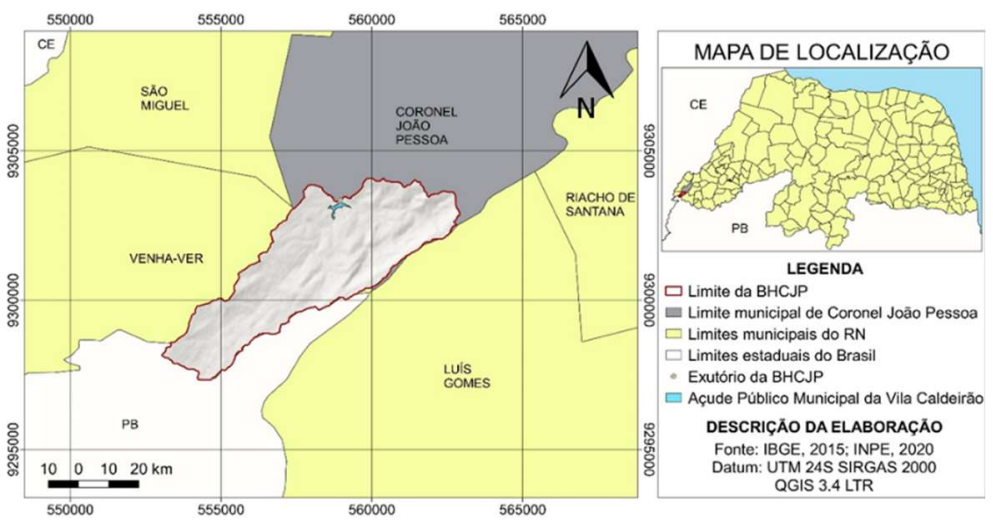

Figura 1: Localização da BHCJP.

A BHCJP encontra-se totalmente inserida na área de abrangência da bacia hidrográfica Apodi/Mossoró (IDEMA, 2008) e apresenta um clima, conforme classificação climática de Köppen-Geiger, do tipo As, isto é, clima tropical com estação seca de verão (ALVARES et al., 2013). A precipitação pluviométrica anual média é de 789,6 mm com período chuvoso de fevereiro a junho, temperaturas médias anuais de 28,1 ${ }^{\circ} \mathrm{C}$ e umidade relativa média anual de 66\% (EMPARN, 2020; IDEMA, 2008).

Segundo dados do Instituto Brasileiro de Geografia e Estatística (IBGE, 2011), o município possuía uma população de aproximadamente 4.772 habitantes distribuídos em uma área territorial de 117,14km², no ano de 2010. Os habitantes dos municípios de Coronel João Pessoa e Venha-Ver destacam-se no espaço rural por apresentarem atividades econômicas voltadas para a agropecuária, uma vez que as características físicas e ambientais da região viabilizam a continuidade de exploração de pequenos agricultores familiares e estabelecimentos rurais para extração de recursos naturais (LIMA, 2018; LIMA et al., 2019).

\section{Procedimentos metodológicos}

\section{Aspectos físicos e ambientais da bacia hidrográfica}

Para o desenvolvimento da pesquisa, empregou-se os softwares Google Earth Pro e QGIS versão 3.4 LTR para elaboração das cartas temáticas para caracterização de alguns atributos físicos e ambientais da unidade territorial. Sendo estes: Hidrografia, Hipsometria, Declividade, Solo, Relevo, Áreas de Preservação Permanente (APPs), bem como Uso e Ocupação do Solo. O critério de escolha desses elementos na área de estudo partiu-se da premissa de que facilitam a compreensão da diversidade e complexidade da paisagem, assim como explicam o fator da antropização do espaço, conforme sugere Gorayeb et al. (2014).

Para coleta de dados, tomou como referência as bases cartográficas no formato de shapefile disponibilizadas junto ao IBGE e Banco de Informações Ambientais (BDIA) do IBGE. Para a representação dos mapas de Rede de Drenagem (Hidrografia), Hipsometria e Declividade, em específico, utilizou-se a camada do tipo raster do Modelo Digital de Elevação (MDE) obtida no TOPODATA, correspondente a folha 06S39_ZN, com resolução espacial de pixel de $30 \mathrm{~m}$. Para a carta temática de Uso e Ocupação do Solo utilizou-se duas cenas no formato raster do Landsat 5 e Landsat 8, baixadas gratuitamente da plataforma Science for a 
Changing World (USGS), ambas com resolução espacial igual a $30 \mathrm{~m}$, selecionadas as bandas 2, 3, 4, 5, 6 e 7 do sensor OLI do Landsat 8 e as bandas 1, 2, 3, 4, 5 e 7 do sensor TM do Landsat 5 para o processo de classificação, cujo identificadores de cenas são LT52160642009324CUB00 e LC82160642019320LGN00, retiradas nas datas de 20 de novembro de 2009 e 16 novembro de 2019, respectivamente. Ambos os dados foram processados nos softwares mencionados com o sistema de coordenadas planas e sistema de referência SIRGAS 2000 UTM 24S.

Para identificação dos tipos de usos da localidade, fatores ambientais que interferem na dinâmica do meio ambiente, bem como o emprego de registros fotográficos, foram realizadas visitas in loco na área de estudo em junho de 2020.

\section{Análise integrada da paisagem}

Para delimitação da bacia e obtenção da rede de drenagem e direção de fluxo de escoamento iniciouse com o pré-processamento do MDE. Após o recorte para a área de interesse, procedeu-se com o preenchimento dos pixels sem dados, recorrendo-se ao menu raster, opção análise e preencher sem dados. A remoção de depressões espúrias foi realizada com o comando Fill sinks (Wang \& Liu), do conjunto de ferramentas Terrian Analysis - Hidrology, do complemento SAGA. Segundo Souza et al. (2017), esse comando corrige possíveis erros do MDE e faz com que o sentido preferencial de escoamento calculado ocorra de forma a representar o fenômeno natural, de maiores para menores elevações.

Seguidamente foi utilizado o algoritmo do GRASS, pela ferramenta r.water.outlet, com base nas coordenadas do ponto de exutório obtidos com auxílio do Google Earth. A rede de drenagem e direção de fluxo de escoamento foram obtidas por meio do módulo r.watershed. Para a análise dos parâmetros morfométricos da BHCJP realizou-se cálculos a partir de parâmetros que caracterizam a forma da bacia, o relevo e a rede de drenagem, conforme metodologia de Nery (2016).

O mapa de hipsometria foi obtido a partir do MDE utilizando-se a ferramenta Análise de Dados Raster e comando r.reclass, na qual definiu-se as classes de altimetria com módulo de 100 m. Além disso, foram geradas curvas de nível com equidistância de 20 metros através da ferramenta contour contida no algoritmo raster, a partir do Filled DEM e com a mesma variação de cota mínima e máxima.

O mapa de declividade, expresso em porcentagem, foi reclassificado com o comando r.reclass. Para a interpretação de declividade, de forma a correlacionar as fases de relevo, foi redefinida de acordo com as seis classes de declividade estabelecidas pela Empresa Brasileira de Pesquisa Agropecuária (EMBRAPA, 1979). Já os de relevo e de solos foram elaborados a partir de arquivos shapes da plataforma BDIA Web do IBGE, que reúne bases temáticas de recursos naturais do território nacional.

Para a delimitação das APPs na BHCJP, considerou-se a faixa marginal de reservatórios e corpos hídricos, ao redor das nascentes, nos topos de morros e encostas com declividades acima de 45으, conforme critérios estabelecidos pela Resolução CONAMA no 303/2002 (BRASIL, 2002) e a Lei no 12.651/2012 (BRASIL, 2012). Para tal, delimitou-se as APPs em áreas com declividade superior à 45ㅇ; em potenciais nascentes com APP's tendo circunferência de raio de 50 m; corpo lótico (1ạ ordem) e um reservatório lêntico em zona urbana 
delimitado com APP de $30 \mathrm{~m}$. Na delimitação não foram considerados corpos hídrico com área superficial de menos de 1 há, conforme dispensa a legislação vigente.

A elaboração das cartas temáticas de uso e cobertura do solo foi realizada com o Semi-Automatic Classification Plugin (SCP), com base nas cenas do Landsat 5 e Landsat 8 em um intervalo de 10 anos (2009 e 2019). No processo de treinamento para classificação foram previamente definidas as classes de vegetação nativa, pastagem/agricultura, solo exposto, água e rocha nua por reconhecimento em campo dos principais usos do solo na área de estudo, e selecionadas as regiões com assinaturas espectrais específicas de cada classe, chamadas de áreas de treinamentos ou ROls. O algoritmo utilizado foi Maximum Likelihood que determina os limites espaciais entre áreas adjacentes considerando valores máximos de probabilidade (PEREIRA et al., 2019). Ressalta-se que nesse processo o objetivo foi gerar mapas detalhados dos principais tipos de uso e ocupação do solo da unidade territorial e levantar dados pertinentes à discussão pretendida no estudo. Esse procedimento de identificação e análise integrada da paisagem é esquematizado na Figura 2.

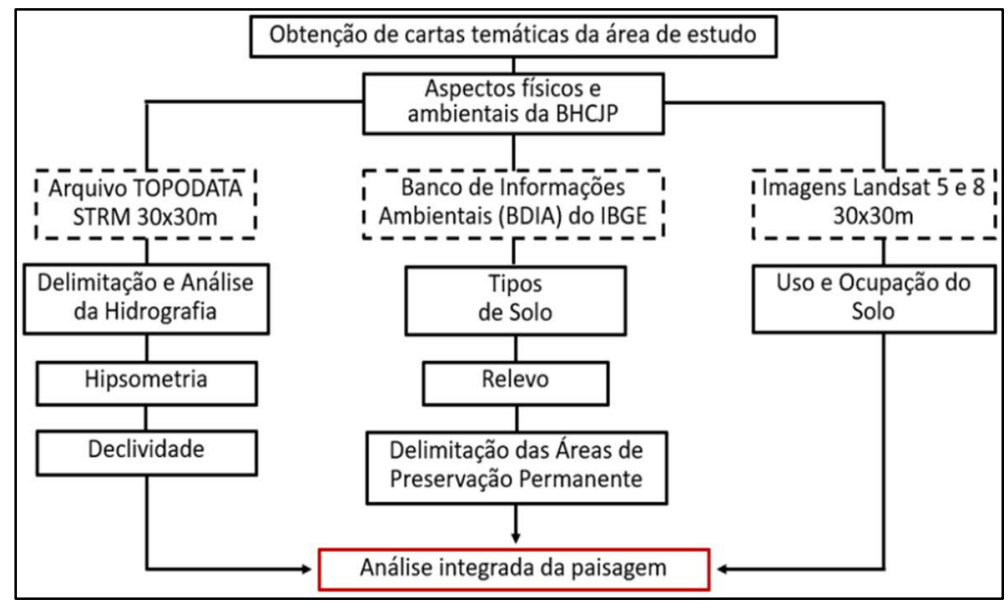

Figura 2: Fluxograma do método adotado no estudo.

\section{RESULTADOS E DISCUSSÃO}

\section{Rede de drenagem}

A BHCJP apresentou um total de 23 drenos, possui uma área de drenagem equivalente a $25,77 \mathrm{~km}^{2}$ e detém uma característica de forma alongada (Figura 3) diante do seu Índice de Circularidade (Ic) com valor igual a 0,371. Dessa forma, Guerra et al. (2015) indicam que a precipitação pluviométrica sobre a bacia hidrográfica se concentra em diferentes pontos, o que favorece o escoamento superficial em períodos chuvosos, que carrega com a água, dentre outros materiais, compostos orgânicos provenientes da produção agrícola que contorna o corpo d'água.

Vale ressaltar ainda que o sistema de drenagem dessa unidade territorial indica ser pouco ramificada diante de sua hierarquia fluvial determinada por Strahler (1957) como sendo de terceira ordem. Além disso, percebe-se também que a bacia apresenta canais retilíneos por apontar um índice de sinuosidade (Sin) de 1,129, conforme classificação realizada por Schumm (1963). De acordo com Santos et al. (2016), canais retilíneos favorecem o transporte de sedimentos ao longo do curso d'água e são intensificados pela 
característica litológica, estrutura geológica e pela declividade dos mesmos.

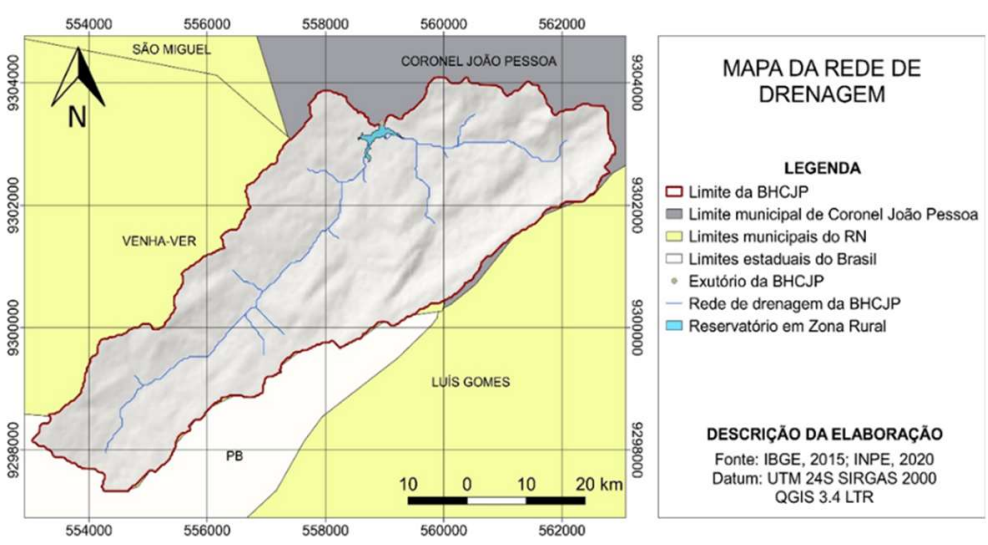

Figura 3: Rede de drenagem da BHCJP.

Sua rede de drenagem é considerada diversificada, uma vez que a área é totalmente banhada por cursos d'água secundários e intermitentes do tipo lótico e, ainda com presença de rios e lagos considerados corpos hídricos do tipo lênticos (MME, 2005). Parte desses recursos hídricos são utilizados para as atividades agrícolas e dessedentação animal que estão alocados nas áreas circunvizinhas da BHCJP. Além disso, os recursos hídricos da região também são destinados para abastecimento hídrico da população (Figura 4).
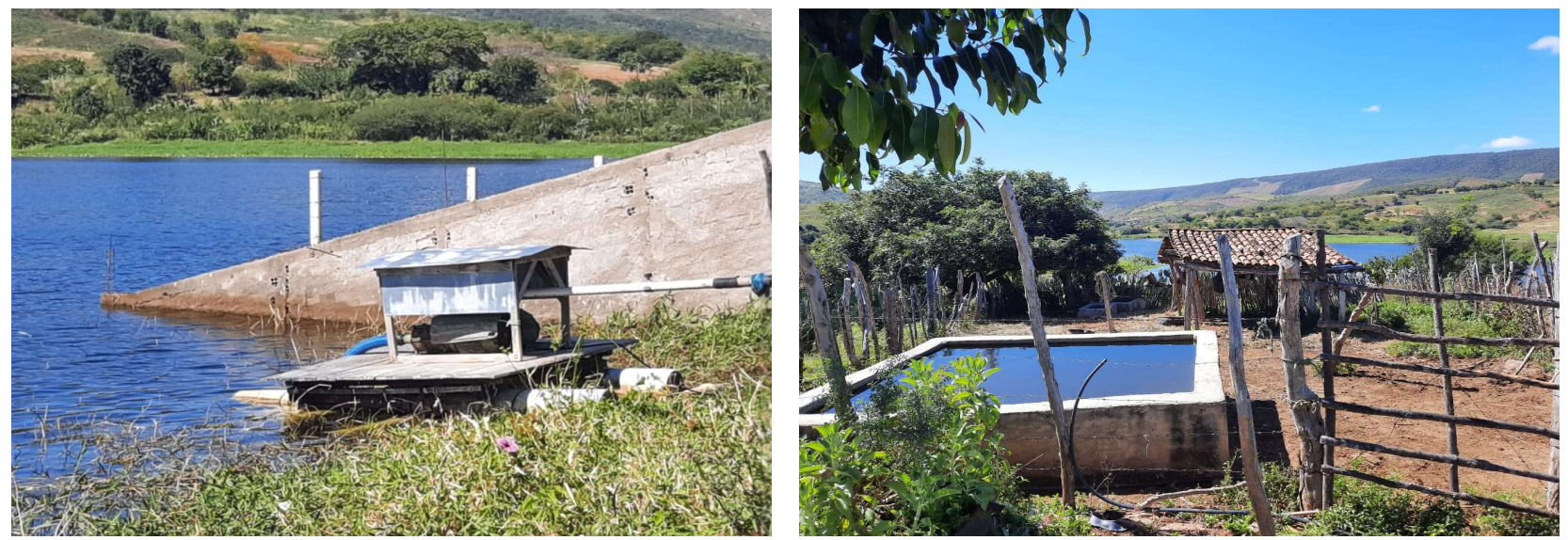

Figura 4: Uso da água pela população no entorno da BHCJP, para consumo humano e dessedentação animal.

Os corpos hídricos presentes no entorno da BHCJP apresentam uma atuação de ocupações antrópicas próximas aos seus leitos. O processo de urbanização presente na região da bacia segue um crescimento natural e contribui para que as moradias se fixem próximas as fontes de águas superficiais (Figura 5). Além disso, vale ressaltar que as regiões rurais, mesmo com uma densidade populacional reduzida, reproduzem a mesma forma de apropriação, quanto a isso, Santos et al. (2014) acrescentam que esse fator é proporcionado porque cidades interioranas apresentam falta de vigilância e aplicação de leis ambientais. Essas formas de ocupações habitacionais contribuem para o aparecimento de diversos problemas ambientais. Dos impactos encontrados é frequente os processos erosivos, contaminação dos solos e das águas superficiais ocasionado pela ausência de saneamento básico (FURTADO et al., 2016).

O município de Coronel João Pessoa/RN apresenta um índice elevado de atividades agropecuárias. De acordo informações antecipadas pelo Censo Agropecuário (IBGE, 2019), foi possível encontrar cerca de 278 estabelecimentos agropecuários, sendo parte deles situados próximas as regiões que apresentam águas 
superficiais como riachos e açudes (LIMA et al., 2019; IBGE, 2019). A partir disso, é possível compreender que o processo de ocupação vai além do habitacional, ocasionando também a produção e reprodução de atividades econômicas.

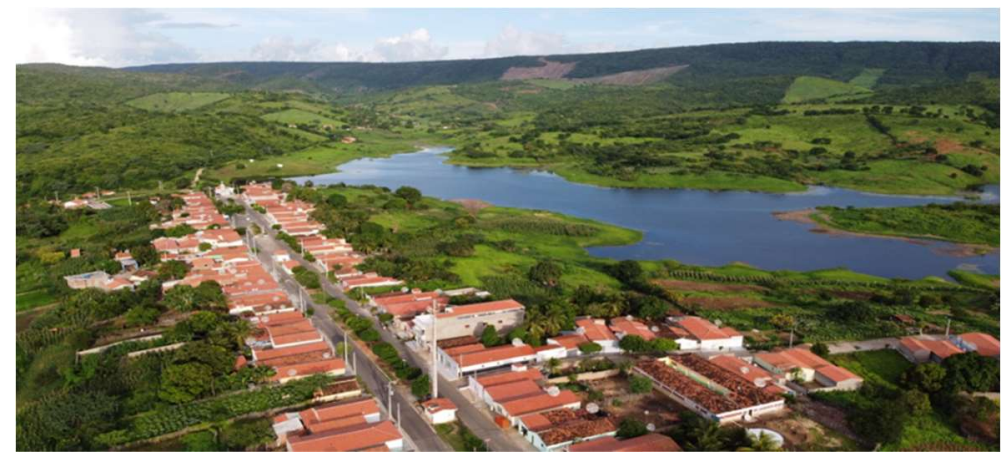

Figura 5: Área urbana nas proximidades do Açude Público Municipal da Vila Caldeirão.

A BHCJP está situada em uma região que apresenta níveis críticos de abastecimento. Sendo assim, para minimizar os efeitos ocasionados pelo uso desproporcional das águas, é preciso implantar políticas que contribuam para o gerenciamento sustentável das águas (FRANÇA et al., 2017; NELSON, 2017).

\section{Hipsometria}

A hipsometria é considerada uma variável importante a ser inserida na análise integrada dos elementos físicos de uma unidade territorial, uma vez que permite a compreensão do terreno e fornece subsídios para o planejamento e ocupação das atividades nesse território (LUCENA et al., 2014). Para Pereira et al. (2018), torna-se uma variável de suma importância nos diagnósticos ambientais, pois favorece uma percepção preliminar dos compartimentos geomorfológicos e as possíveis áreas sujeitas aos deslizamentos de encostas e suscetíveis às inundações.

Dessa forma, destaca-se na Figura 6 a espacialização do perfil topográfico da BHCJP representada pelos valores altimétricos das curvas de nível de $20 \mathrm{~m}$ de equidistância vertical.

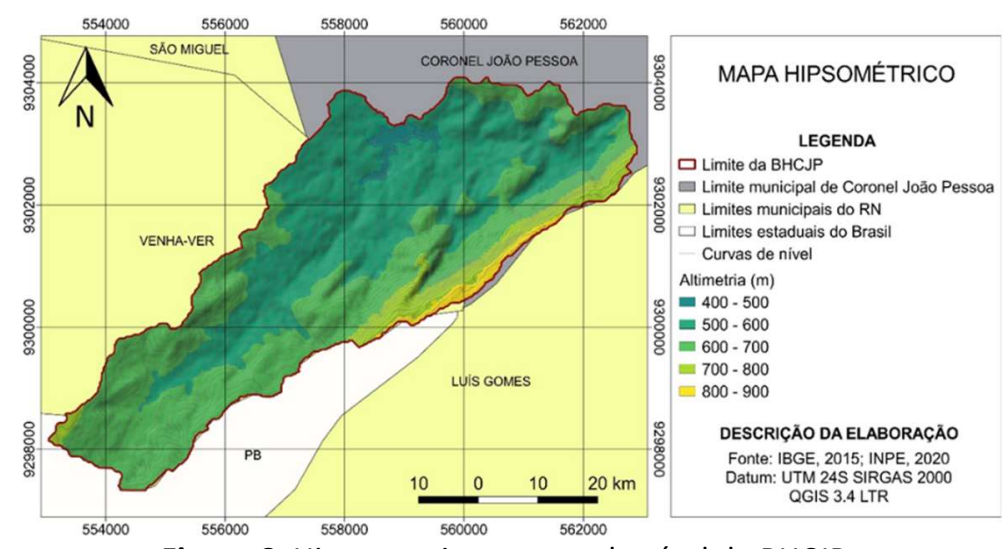

Figura 6: Hipsometria e curvas de nível da BHCJP.

Conforme características da topografia, verificou-se que as maiores altitudes da bacia (Hmáx) e do canal principal (HCmáx) são 836,73 m e 620,60 m, respectivamente. Enquanto, que a menor altitude da bacia (Hmín) e do canal principal (HCmín) correspondem ambos a 502,71 m, o que registrou uma amplitude 
altimétrica $(\Delta \mathrm{H})$ de 334,015 m na unidade territorial em apreço. Dessa forma, Martins et al. (2019) definem a geomorfologia da região como relevos isolados com altitudes superiores à do entorno, frequentemente apresentando vertentes íngremes e sinuosas.

Para Silva et al. (2016), as variações altimétricas de uma bacia hidrográfica também são importantes fatores no registro de valores mínimos e máximos de temperatura, evaporação e precipitação, como também para as formas de uso do solo, e a exposição das vertentes. Uma vez que, quanto maior o desnível de uma determinada área, maior será seu escoamento, o que poderá resultar em uma alteração direta nos elementos que compõem a paisagem. Dessa forma, percebe-se, por meio da hipsometria, que maiores valores nas extremidades do território evidenciam uma maior susceptibilidade aos riscos.

Diante disso, verifica-se por meio de cálculos morfométricos, que a BHCJP apresenta alta propensão a grandes enchentes em condições normais de precipitação, associados aos valores de baixo coeficiente de compacidade $(0,398)$ e fator de forma elevado $(1,629)$. No entanto, em decorrência de um período prolongado de escassez hídrica nos municípios que contemplam em maior totalidade a bacia, entre os anos de 2012 a 2018 (EMPARN, 2020), o quantitativo de precipitações se demonstraram insuficientes para a reposição dos reservatórios, o que ocasionou um colapso no abastecimento dessas localidades que dependiam dos recursos hídricos, como também limitou o desenvolvimento de atividades agrícolas.

\section{Relevo}

Na BHCJP caracteriza-se em sua geoforma com picos elevados e um relevo predominantemente serrano, denominado Serra do Pereiro (Figura 7).

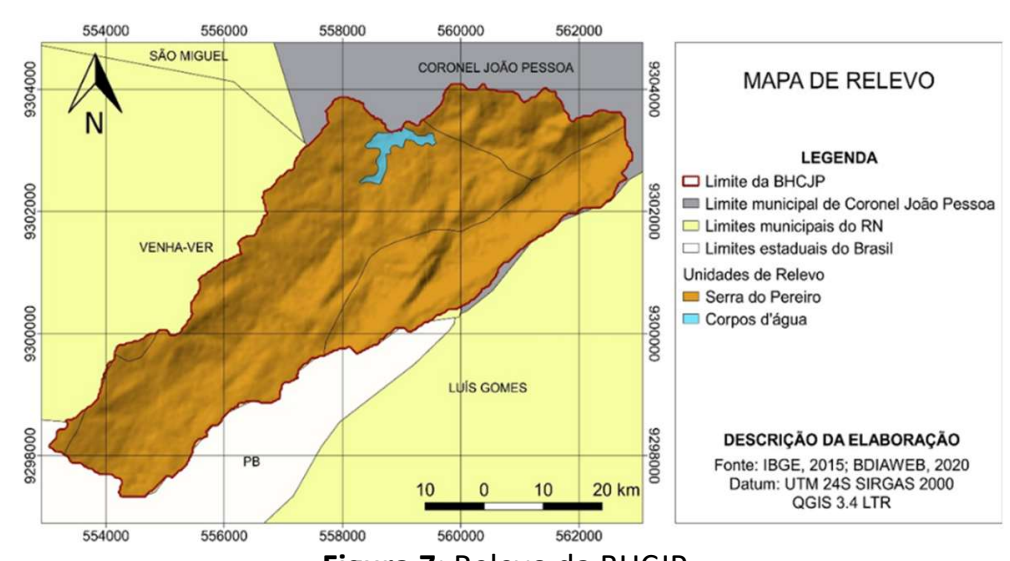

Figura 7: Relevo da BHCJP.

Esse tipo de relevo situa-se em regiões do sudoeste do estado do Ceará, como também na divisa entre os estados do Rio Grande do Norte e Paraíba. Segundo Martins et al. (2019), é característico de regiões distantes de áreas costeiras com um clima subúmido. Ainda conforme os autores, em altitudes inferiores a $600 \mathrm{~m}$ predomina um clima que se assemelha ao do sertão semiárido com feições caracterizadas como 'serras secas' e em regiões com topografia mais elevada descreve-se um caráter de serra úmida que condiciona uma série de variáveis ambientais e inclusive sociais.

Geologicamente esse território apresenta formas tabulares de relevos, de topo plano, com diferentes ordens de grandeza e de aprofundamento de drenagem, separados geralmente por vales de fundo plano 
(IDEMA, 2008). Dessa forma, embora essa região semiárida, na qual a unidade territorial está inserida, apresente um fenômeno da escassez hídrica ocasionado pela elevada temperatura associada aos altos índices de evaporação e episódios de precipitações irregulares, Lima et al. (2019) retratam que o seu relevo proporciona a inundação de diversas áreas por meio de seus canais fluviais.

\section{Declividade}

A declividade é um fator fundamental com influência direta no estado de conservação da unidade de bacia (RODRIGUES et al., 2015) e sua análise, portanto, possibilita evidenciar a distribuição das inclinações de uma superfície do terreno.

Nesse sentido, tem-se que a BHCJP se caracteriza segundo a EMBRAPA (1979) por apresentar uma declividade predominantemente ondulada (8 a 20\%) e forte ondulada (20-45\%), conforme ilustra a Figura 8.

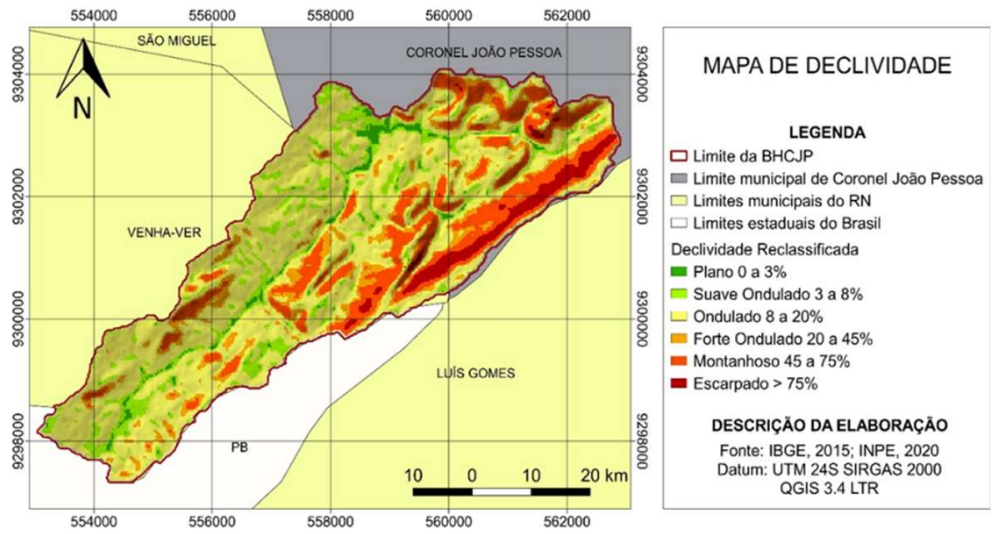

Figura 8: Declividade da BHCJP conforme classificação da EMBRAPA (1979).

Para áreas classificadas como relevo ondulado e forte ondulado, Alves et al. (2019) afirmam que o escoamento superficial é muito rápido e por esse motivo os solos ficam mais susceptíveis a erosões, sendo necessária a inserção de técnicas de conservação avançadas para o uso agrícola nesta região. Além disso, áreas que possuem maior declividade devem ser destinadas a preservação ambiental (SANTANA et al., 2019).

Constatou-se ainda a presença de relevo plano (0 a 3\%) e suave ondulado ( 3 a $8 \%$ ) em toda região da rede de drenagem. Pereira et al. (2019) relatam que em áreas planas as atividades antrópicas são mais intensas, principalmente a agricultura e a agropecuária, visto que, essas são utilizadas para o cultivo e criação de animais, implicando em locais que poderão ser degradados em decorrência do uso. Ainda, se faz necessário enfatizar que regiões muito planas podem ser consideradas frágeis, uma vez que estão susceptíveis à fenômenos naturais como as enchentes, por exemplo (LOPES et al., 2020).

\section{Solos}

De acordo com a Figura 9, percebe-se que as áreas ao entorno da BHCJP apresentam solos de tipo Argissolo vermelho-amarelo e Argissolo vermelho, ambos eutróficos.

Os solos Argissolo vermelho-amarelo eutrófico presentes nos municípios que contemplam a unidade de planejamento, têm sua origem no grupo Barreiras de rochas cristalinas. Apresenta horizontes com presença de argila e com coloração que varia entre vermelho e amarelo, esse aspecto é provocado pela 
presença de óxido de ferro hematita e goethita. Seu caráter eutrófico, contribui para o surgimento de saturação por base $\geq 50 \%$ em quase toda extensão do horizonte B, sendo assim, considerados solos com elevada fertilidade (SANTOS et al., 2018).

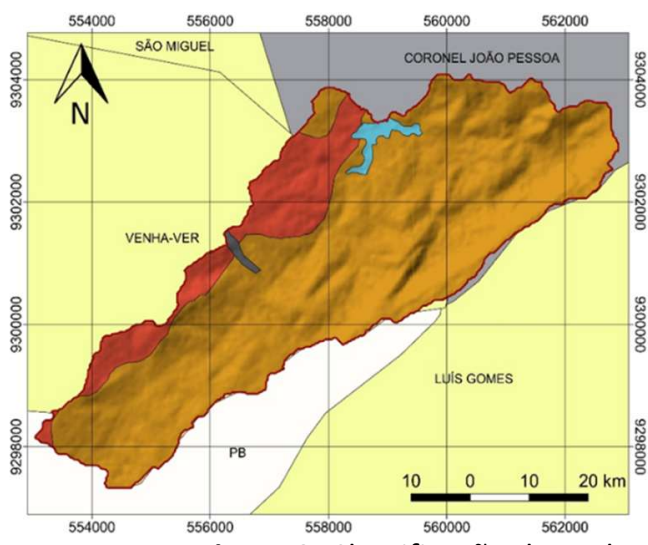

Figura 9: Classificação dos solos da BHCJP.
MAPA DE SOLOS

Limite municipal de Coronel Joăo Possog L Limites municipais do RN Limites estaduais do Brasil Solos - Classificaçâa Corpos d'ägu Argissolo Vermelho-Amarelo Eutrofico - Argissolo Vermelho Eutrófico

DESCRIÇÃO DA ELABORAÇÃO

Fonte: IBGE, 2015; BDIAWEB, 2020 Datum: UTM 24S SIRGAS 2000

O Argissolo vermelho eutrófico apresenta elevada textura argilosa, uma estrutura granular de proporção pequena e com presença de pedregosidade e teor elevado de fertilidade e coloração avermelhada. Entre os minerais que compõem esse solo, é possível encontrar vestígios de quartzo, caulinita e ilita (AZEVEDO et al., 2013). Além disso, vale destacar que esse tipo de solo apresenta habitualmente profundidade elevada, concentração de argila e seu aparecimento está associada a áreas que possuem relevos ondulados e suavemente ondulados características essas que em conjunto os tornam susceptíveis a processos erosivos (FREITAS et al., 2011), ver Figura 10.
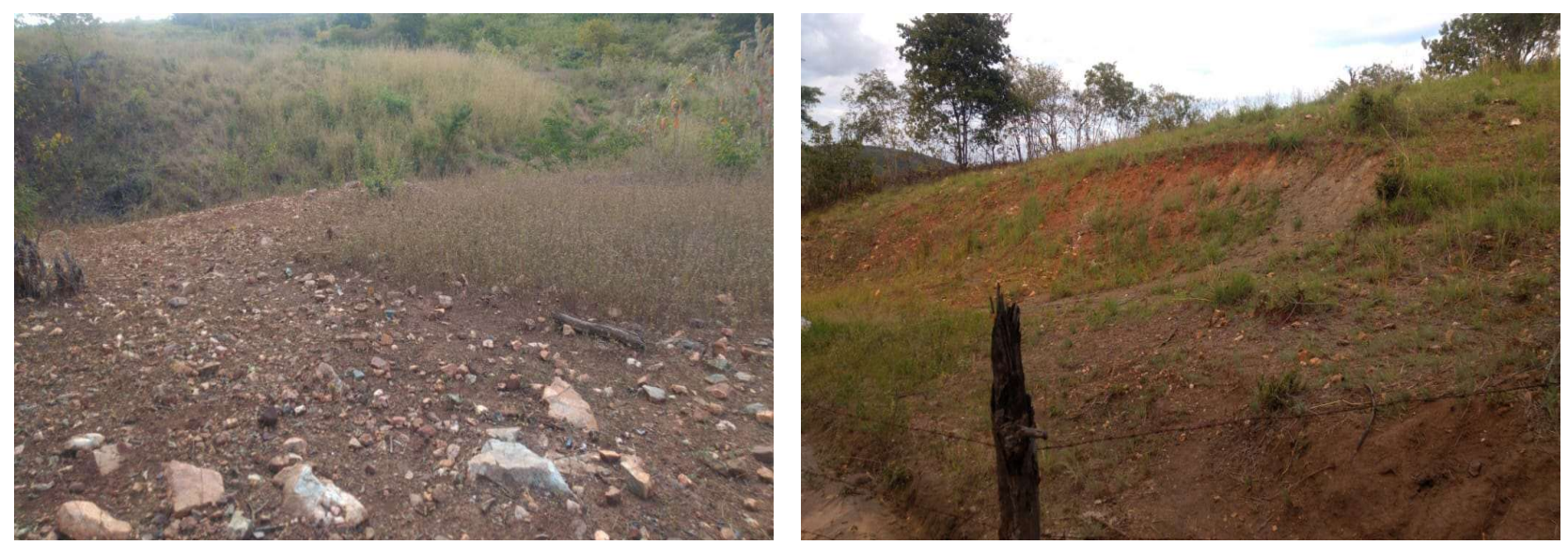

Figura 10: Solo exposto com afloramento rochoso e área declive com ausência parcial de vegetação nativa e susceptibilidade à erosão.

Ao analisar as potencialidades dos solos presentes no entorno da BHCJP, Lima et al. (2019) afirmam que a qualidade dos solos, presente predominantemente no município de Coronel João Pessoa/RN, representam um elemento importante para continuidade das atividades agrícolas que destina parte da sua produção para a subsistência e outra para comercialização no mercado da região. Porém, ressaltam que a localidade possui limitações, provocadas principalmente por instabilidades climáticas que proporcionam longos períodos de estiagem e afeta a principal atividade econômica local. 


\section{Delimitação de APPs}

A delimitação das Áreas de Preservação Permanente na BHCJP, tendo por base a Resolução CONAMA no 303/2002 e a Lei no 12.651/2012 do novo Código Florestal, possibilitou identificar as áreas protegidas para a preservação e garantia da qualidade ambiental (Figura 11).

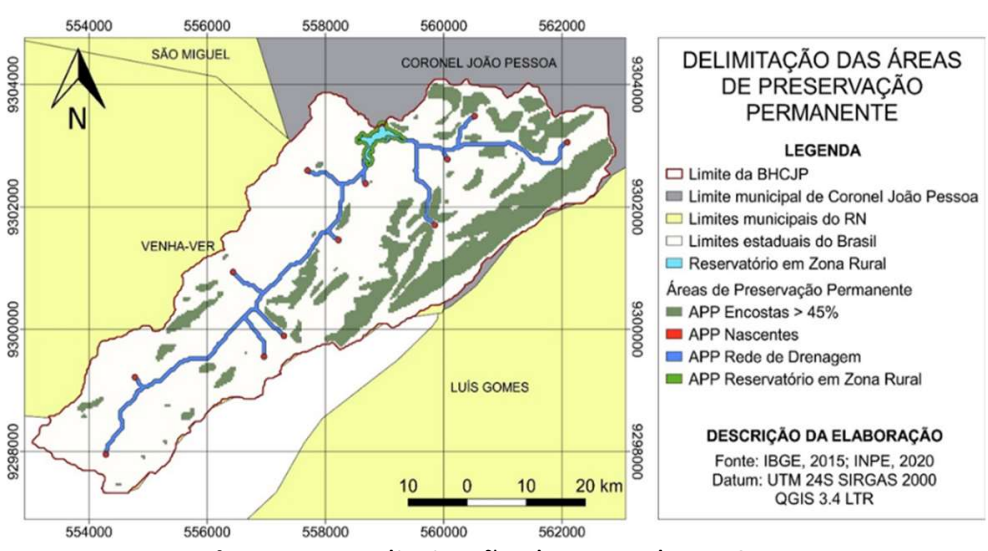

Figura 11: Delimitação de APPs da BHCJP.

No caso deste estudo em específico, o uso do solo na região como agricultura, pastagem, instalação de edifícios com rede de esgoto, dentre outros, tem alertado para possíveis fragilidades ambientais nessas áreas (Figura 12). Dessa forma, impactos ambientais decorrentes do uso indevido das APPs ocasionam enchentes, assoreamento dos rios, poluição das águas, probabilidade de extinção de afluentes, modificação da fauna e entre outros (SPETH et al., 2019).
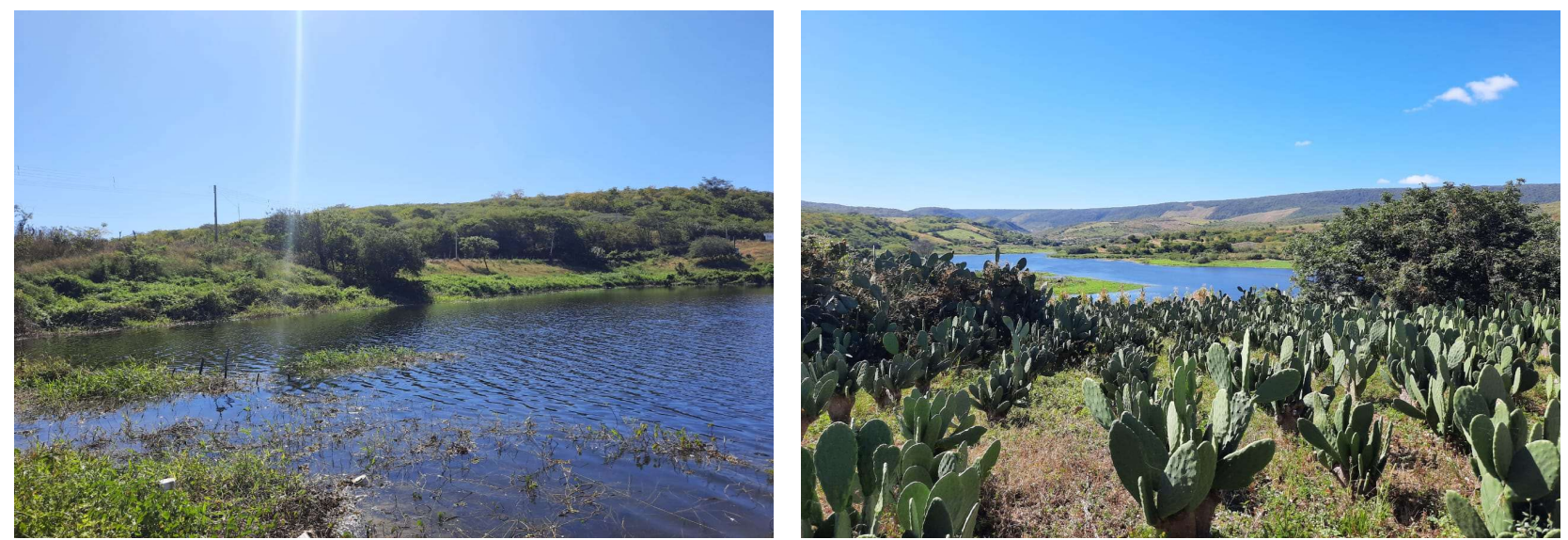

Figura 12: Fragmentos de APP no entorno da BHCJP e área ocupada por agricultura familiar às margens da calha fluvial.

Neste estudo, delimitou-se as áreas com declividade acima de 45\%, baseando-se na premissa da grande importância que há em se preservar tais regiões. Segundo o Código Florestal Brasileiro (BRASIL, 2012), esses espaços devem ter $100 \%$ de sua mata ciliar preservada, tendo em vista que são regiões propensas a sofrerem processos erosivos quando não possuem sua vegetação nativa. Além disso, verifica-se a presença de nascentes na rede de drenagem e, dessa maneira, a delimitação das APPs desses elementos torna-se necessário tendo em vista as legislações vigentes. Em concordância, Luppi et al. (2015) afirmam que essa delimitação tem grande importância já que é primordial a vida útil dos rios que por elas são abastecidos. 


\section{Uso e cobertura do solo}

Na Figura 13 observam-se as alterações ocorridas nos compartimentos ambientais da BHCJP, decorrentes de dois mapas de uso e cobertura do solo em temporalidade distinta com um intervalo de dez anos (2009-2019).

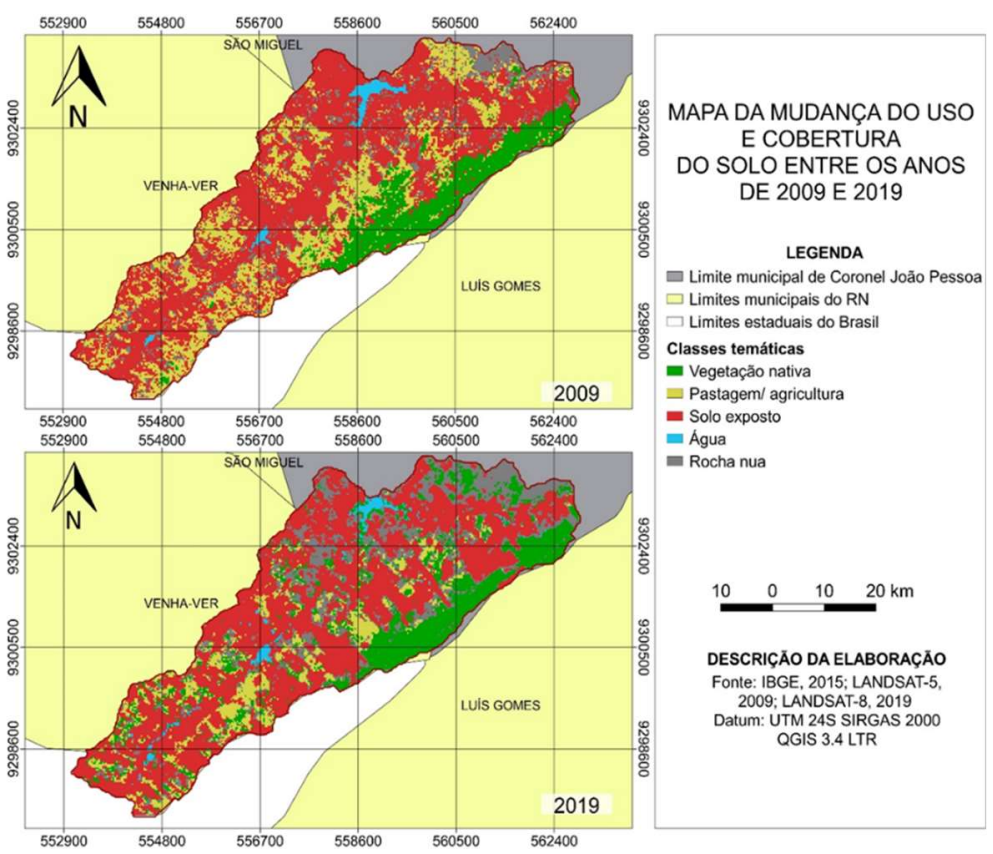

Figura 13: Cartas temáticas de Uso e cobertura do solo da BHCJP em 2009 e 2019.

Além disso, por meio da mensuração das classes expostas no Quadro 1, é possível averiguar que houveram alterações na configuração ambiental da BHCJP durante os dois momentos analisados na pesquisa.

Quadro 1: Variação das classes de uso e cobertura do solo, nos anos de 2009 e 2019.

\begin{tabular}{|l|l|l|l|l|}
\hline Classe & Área em 2009 (ha) & Área em 2019 (ha) & Evolução em (ha) & Evolução em (\%) \\
\hline Vegetação nativa & 332,6400 & 444,7800 & $+112,14$ & $+33,7121$ \\
\hline Pastagem/ agricultura & 607,8600 & 256,6800 & $-351,18$ & $-57,7732$ \\
\hline Solo exposto & 1362,1500 & 1362,9600 & $+0,81$ & $+0,0595$ \\
\hline Água & 0,32490 & 0,39150 & $+0,0666$ & $+20,4986$ \\
\hline Rocha nua & 238,8600 & 470,4300 & $+231,57$ & $+96,9480$ \\
\hline Total & 2574,0000 & 2574,0000 & - & - \\
\hline
\end{tabular}

Ao analisar a presença da vegetação nativa na região da BHCJP percebe-se que houve uma evolução no número de áreas verdes à medida que sobreveio um decréscimo de áreas ocupadas por atividades agrícolas e de pastagem. No intervalo entre 2009 a 2019, verificou-se um crescimento de 33,71\% no número de áreas ocupadas pela vegetação, enquanto que as regiões atribuídas antes as atividades de cultivo e pastagem obtiveram uma diminuição de $57,77 \%$ em seu uso. Isso pode ser explicado, de acordo com Romeiro (2019), pela diminuição das ações antrópicas em decorrência da queda das atividades agrícolas, fiscalização ou cumprimento da legislação. Silva et al. (2018), em complemento, revelam que o processo de remoção da vegetação em áreas de caatinga se desenvolve conforme o seu uso para as atividades econômicas, que são a base de sustento das populações dessa região. Dessa forma, com a diminuição das ações promovidas pelas atividades rurais na região da BHCJP foi possível evidenciar a expansão da flora nativa.

O processo de análise temporal na paisagem da BHCJP demonstrou que não houve apenas uma 
expansão da vegetação nativa, mas também um aumento significativo das águas superficiais. $\mathrm{O}$ quantitativo das águas presentes entre os períodos de 2009 a 2019 representou um crescimento de 20,4\%. Todavia, de acordo com dados da Empresa de Pesquisa Agropecuária do Rio Grande do Norte (EMPARN, 2020), o índice de precipitação pluviométrica no município de Coronel João Pessoa/RN acumulado durante os meses de 2009 correspondeu a 1462,1 mm/ano, enquanto que no ano de 2019 o acumulativo foi de apenas 789,6 $\mathrm{mm} / \mathrm{ano}$. No entanto, essa queda evidenciada não refletiu na diminuição do volume disponível de água, que apresentou um quantitativo maior comparado com o ano de 2009. Esse fato pode estar associado pela diminuição das atividades agropastoris no período de estudo e com isso houve uma menor dependência desse recurso hídrico na localidade.

Silva et al. (2020a) afirmam que a partir de resultados obtidos em estudos na Bacia Hidrográfica do Açude Santa Cruz de Apodi/RN, que o processo de diminuição do volume das águas superficiais é caracterizado por uma maior intervenção no uso e ocupação do solo em intervalos de tempo. Da mesma forma, Lira (2015) reitera que a apropriação inadequada dos corpos hídricos gera uma cadeia de impactos ambientais de modo a motivar alterações no volume dos corpos hídricos.

Embora verifica-se uma diminuição das ações antrópicas, não foi o suficiente para reduzir a área de solo exposto, assim como a presença de afloramento rochoso ao longo da superfície terrestre da bacia. Entre os anos de 2009 a 2019 diagnosticou um crescimento em torno de 0,06\% de áreas com solos expostos decorrentes, principalmente de áreas desmatadas em elevadas altitudes da serra na localidade. Enquanto que a presença de rocha nua, onde antes era ocupada especialmente por áreas agricultáveis e pastagens, obteve um acréscimo significativo de 96,95\%, com relação à toda unidade territorial. De acordo com Silva et al. (2020b), as áreas onde se encontram solos expostos estão mais susceptíveis aos processos erosivos e consequentemente perdem a sua camada orgânica, tornando o solo pobre em nutrientes. Em complemento, Silva et al. (2020) exprimem que essas alterações ambientais são resultantes de uma deficiência na gestão dos recursos naturais.

Nessa perspectiva de análise do uso e cobertura do solo é possível identificar que no período de 2009 a 2019 a paisagem sofreu algumas alterações, e com isso, também indica modificações nos atributos físicos e ambientais da unidade territorial. Dessa forma, em relação a cobertura vegetal, verifica-se que está sofreu uma redução em áreas com declividade acima de 45\%, logo, é possível inferir que houve crescente desmatamento da área devido, principalmente, as atividades antrópicas recorrentes nestas áreas, como a agricultura. Esse fator está em desacordo com o proposto pelo Código Florestal Brasileiro, uma vez que, esta região se encontra em área de preservação. Silva et al. (2020) ao analisarem o uso e ocupação do solo na Bacia Hidrográfica do Açude Santa Cruz do Apodi/RN, verificaram que em áreas de alta declividade, as terras eram preservadas, apresentando um cenário oposto ao encontrado neste estudo.

A alta declividade dessa área, apresentada no mapa de hipsometria (Figura 6) e de declividade (Figura 8), influi diretamente no escoamento superficial, pois a alta velocidade reduz a infiltração de água, e por se tratar de um relevo mediano, como ilustrado no mapa de relevo (Figura 7), torna-se um ambiente susceptível a erosão. Além disso, a redução da cobertura vegetal resulta no aumento do solo exposto, sendo estes fatores 
preponderantes para o desenvolvimento da erosão, conforme verifica-se na dinâmica multitemporal do presente estudo. Corroborando com estes resultados, Rodrigues et al. (2015) sugerem que em regiões com alta declividade é essencial a recomposição florestal para a conservação dos recursos hídricos e da biodiversidade.

A paisagem da bacia é constituída por uma rede de drenagem que contribui para o desenvolvimento da agricultura e pecuária nesta região. Porém, identifica-se que em 2019 (Figura 13) embora exista um aumento na disponibilidade hídrica (20\%), elemento essencial para atividades agropastoris, houve uma redução significativa dessas atividades rurais. Estes fatores são decorrentes principalmente do uso intensivo do solo que acarretaram em infertilidade e compactação deste, comprometendo o surgimento de novas vegetações nessas localidades e alterando a paisagem. Fernandes et al. (2015) ao observarem as modificações do uso e de cobertura da terra na região semiárida de Sergipe, identificaram que o aumento de solo exposto estava relacionado com o aumento das atividades antrópicas seguidas de abandono da área, principalmente áreas ocupadas por pastagens.

Nessa perspectiva, é notório que os elementos físicos que compõem a paisagem influem diretamente no comportamento das ações desenvolvidas nessas regiões. A declividade, relevo, rede de drenagem, o tipo de solo, a vegetação, dentre outros, são fatores essenciais na construção integrada da paisagem e suas alterações, sejam estas antrópicas e/ou naturais. A análise detalhada dessas áreas permite apontar caminhos para a gestão dos territórios pelo poder público, além de possibilitar que as atividades humanas realizadas nestas áreas causem o mínimo de impactos negativos ao meio natural.

\section{CONCLUSÕES}

A BHCJP possui uma rede de drenagem pouco ramificada, com hierarquia fluvial de terceira ordem, banhada por cursos d'água do tipo lótico e lênticos, no qual parte desses recursos hídricos são utilizados para as atividades agrícolas, dessedentação animal e abastecimento hídrico da população, mas que apresenta níveis críticos para o abastecimento, sendo necessário implantar políticas que contribuam para o gerenciamento sustentável das águas, afim de minimizar os efeitos ocasionados pelo uso desproporcional desses recursos.

Quanto a hipsometria, destaca-se que a BHCJP apresenta alta propensão a grandes enchentes em condições normais de precipitação. No entanto, em decorrência de um período prolongado de escassez hídrica nos municípios que contemplam em maior totalidade a bacia, o quantitativo de precipitações se demonstrou insuficiente para a reposição dos reservatórios, resultando em colapso no abastecimento e limitação do desenvolvimento de atividades agrícolas.

O relevo da BHCJP caracteriza-se em sua geoforma com picos elevados e um relevo predominantemente serrano, com vertentes íngremes e sinuosas. Geologicamente esse território apresenta formas tabulares de relevos, de topo plano, com diferentes ordens de grandeza e de aprofundamento de drenagem, separados por vales de fundo plano. Embora localize-se em região semiárida, que predomina a escassez hídrica, seu relevo proporciona a inundação de diversas áreas por meio de seus canais fluviais. 
A bacia possui uma declividade predominantemente ondulada e forte ondulada, onde o escoamento superficial é muito rápido e por esse motivo os solos ficam mais susceptíveis a erosões, sendo necessária a inserção de técnicas de conservação avançadas para o uso agrícola nesta região.

Na delimitação das APPs, constatou-se que o uso do solo na região como agricultura, pastagem, dentre outros, têm alertado para possíveis fragilidades ambientais nessas áreas. Para tal, delimitou-se apenas as áreas com declividade acima de 45\%, onde esses espaços devem ter sua mata ciliar preservada, uma vez que são regiões propensas a sofrerem processos erosivos quando não possuem sua vegetação nativa, além da presença de nascentes na rede de drenagem.

Ao analisar o uso e cobertura do solo ao longo de 10 anos, houve uma evolução no número de áreas verdes e um decréscimo de áreas ocupadas por atividades agrícolas e de pastagem. Houve uma expansão da vegetação nativa e também um aumento significativo das águas superficiais. Constatou uma diminuição das ações antrópicas, embora um crescimento em torno de 0,06\% de áreas com solos expostos decorrentes, principalmente de áreas desmatadas em elevadas altitudes da serra na localidade. Enquanto que a presença de rocha nua, obteve um acréscimo significativo de 96,95\%, com relação à toda unidade territorial.

Com tudo, é possível identificar que no período estudado a paisagem sofreu algumas alterações nos atributos físicos e ambientais da unidade territorial A análise detalhada destes permite apontar caminhos para a gestão dos territórios pelo poder público, além de possibilitar que as atividades humanas realizadas nestas áreas causem o mínimo de impactos negativos ao meio natural.

\section{REFERÊNCIAS}

ALEXANDRE, F. S.; CANDEIAS, A. L. B.; GOMES, D. D. M.. Modelagem cartográfica para a delimitação das paisagens da bacia hidrográfica do Alto Curso do Rio MundaúPernambuco/Alagoas, Nordeste, Brasil. Revista Brasileira de Geografia Física, v.12, n.07, p.2489-2502, 2019.

ALVARES, C. A.; STAPE, J. L.; SENTELHAS, P. C.; GONÇALVES, J. L. M.; SPAROVEK, G.. Köppen's climate classification map for Brazil. Meteorologische Zeitschrift, n.22, n.6, p.711-728, 2013. DOI: https://doi.org/10.1127/0941-2948/2013/0507

ALVES, W. S.; MARTINS, A. P.; AQUINO, D. S.; MORAIS, W. A.; PEREIRA, M. A. B.; SALEH, B. B.. Análise do uso da Terra, da Cobertura Vegetal e da Morfometria da Bacia do Ribeirão Douradinho, no Sudoeste de Goiás, Brasil. Revista Brasileira de Geografia Física, v.12, n.3, p.1093-1113, 2019. DOI: https://doi.org/10.26848/rbgf.v12.3.p1093-1113

AZEVEDO, D. G.; GOMES, R. L.; MORAES, M. E. B.. Bacia do rio Buranhém: análise integrada da paisagem. In: MORAES, M. E. B.; LORANDI, R.. Métodos e técnicas de pesquisa em bacias hidrográficas. Ilhéus: Editus, 2016. p.103-119. DOI: https://doi.org/10.7476/9788574554433.0006

AZEVEDO, M. F. C.; GARNIER J.; CAMPOS, J. E. G.; CUNHA, S. C.. Estudo do parâmetro solo nos métodos de determinação de aquíferos usando colunas de solos. In: CONGRESSO BRASILEIRO DE CIÊNCIA DO SOLO, 34. Anais. Florianópolis: SBCS, 2013.

BRASIL. Lei n. 12.651, de 25 de maio de 2012. Dispõe sobre a proteção da vegetação nativa, e dá outras providências. Brasília: DOU, 2012.

BRASIL. Resolução CONAMA n. 303, de 20 de mar. 2002. Dispões sobre parâmetros, definições e limites de Áreas de Preservação Permanente. Brasília: DOU, 2002.

EMBRAPA. Empresa Brasileira de Pesquisa Agropecuária. Serviço Nacional de Levantamento e Conservação de Solos (Rio de Janeiro, RJ). In: REUNIÃO TÉCNICA DE LEVANTAMENTO DE SOLOS. Anais. Rio de Janeiro: EMBRAPA, 1979.

EMPARN. Empresa de Pesquisa Agropecuária do Rio Grande do Norte. Precipitação Acumulada: Rio Grande do Norte. Monitoramento pluviométrico. Natal: Boletim diário, 2020.

EUGENIO, F. C.; SANTOS, A. R.; FIEDLER, N. C.; RIBEIRO, G. A.; SILVA, A. G.; SOARES, V. P.; GLERIANI, J. M.. Mapeamento das áreas de preservação permanente do estado do Espírito Santo, Brasil. Ciência Florestal, v.27, n.3, p.897-906, 2017. DOI: https://doi.org/10.5902/1980509828639

FERNANDES, M. R. D. M.; MATRICARDI, E. A. T.; ALMEIDA, A. Q. D.; FERNANDES, M. M.. Mudanças do Uso e de Cobertura da Terra na Região Semiárida de Sergipe. Floresta Ambiental, v.22, n.4, p.472-482, 2015. DOI: https://doi.org/10.1590/2179-8087.121514

FRANÇA, J. M. F.; MORENO, J. C.. Uma reflexão sobre os impactos causados pela seca no Rio Grande do Norte de 
2012 a 2016. Parcerias Estratégicas. v.22, n.44, p.213-232,

2017. DOI: https://doi.org/10.1590/S141543662013000400013

FREITAS, P. L.; DONAGEMMA, G; K.; LUMBRERAS, J. F.; SILVA, F. C.; JUNIOR, P. A. V.; FINOTO, E. L.. Propriedades físicas e químicas de um Argissolo vermelho na reforma de canavial para produção de oleaginosas. In: CONGRESSO DE CIÊNCIAS DO SOLO, 33. Anais. Uberlândia: ICIAG, 2011.

FURTADO, Z. N. C.; FURTADO, A. C. N. A.; BIANCHI, G.. Aspecto do meio físico, da ocupação urbana e impactos ambientais presentes na bacia do Córrego Machadinho. Revista Ciência ANAP Brasil, v.9, n.16, p.54-69, 2016. DOI: https://doi.org/10.17271/1984324091620161441

GORAYEB, A.; PEREIRA, L. C. C.. Análise integrada das paisagens de bacias hidrográficas na Amazônia Oriental. Fortaleza: Imprensa Universitária, 2014.

GUERRA, S. M. S.; SILVA, A. M. R. B.; ARAUJO, S. P.; CORRÊA, M. M.; SILVA, V. L.; SANTOS, B. R. T.. Caracterização morfométrica e avaliação da qualidade da água da Bacia Hidrográfica de Bita, Ipojuca/PE. Revista Brasileira de Geografia Física, v.8, n.3, p.759-775, 2015.

IBGE. Instituto Brasileiro de Geografia e Estatística. Censo Agropecuário 2017. IBGE: Rio de Janeiro, 2019.

IBGE. Instituto Brasileiro de Geografia e Estatística. Censo Demográfico 2010. IBGE: Rio de Janeiro, 2011.

IDEMA. Instituto de Desenvolvimento Sustentável e Meio Ambiente. Perfil do seu município: Coronel João Pessoa. IDEMA: Natal, 2008.

LIMA, J. A. B.; BARRETO FILHO, B. F.. A atividade canavieira no município de Coronel João Pessoa/RN. Revista GeoNordeste, n.3, p.205-226, 2019.

LIMA, R. I. B. R.. Gerenciamento dos recursos hídricos em Venha-Ver/RN. Monografia (Bacharelado em Ciência e Tecnologia) - Universidade Federal Rural do Semiárido, Pau dos Ferros, 2018.

LIRA, M. M. P.. Análise do uso e ocupação do solo no entorno do reservatório poço da cruz, Pernambuco - Brasil. Dissertação (Mestrado em Engenharia Civil) - Universidade Federal de Pernambuco, Recife, 2018.

LOPES, J. A.; RIBEIRO, V. S.; SANTOS, J. S.; SANTOS, J. N.; ARAÚJO, M. S.; PYLES, M. V.; SILVA, F. B.. O Cenário de Fragilidade Ambiental do Baixo Curso do Rio Mearim. Revista Brasileira de Geografia Física, v.13, n.1, p.102-120, 2020. DOI:

https://doi.org/10.26848/rbgf.v13.1.p102-120.

LUCENA, M. M. A.; FREIRE, E. M. X.. Análise Integrada da Paisagem por meio do método GTP

(Geossistema/Território/Paisagem) em um Complexo Serrano do Semiárido brasileiro. Gaia Scientia, v.8, n.1, p.306-325, 2014.

LUPPI, A. S. L.; SANTOS, A. R.; EUGENIO, F. C.; FEITOSA, L. S. A.. Utilização de geotecnologia para o mapeamento de áreas de preservação permanente do município de João Neiva, ES. Floresta e Ambiente, v.22, n.1, p.13-22, 2015. DOI: https://doi.org/10.1590/2179-8087.0027.

MARTINS, J. G.; CLAUDINO-SALES, V.. Paisagem geomorfológica e geografia ambiental do Maciço do Pereiro, Estado do Ceara, Nordeste do Brasil. Revista Equador, v.8, n.1, p.1-25, 2019.

MOREIRA, T. R.; SANTOS, A. R.; DALFI, R. L.; CAMPOS, R. F.; SANTOS, G. A.; EUGENIO, F. C.. Confronto do uso e ocupação da terra em Apps no município de Muqui, ES. Floresta e Ambiente, Rio de Janeiro, v.22, n.2, p.141-152, 2015. DOI: http://dx.doi.org/10.1590/2179-8087.019012

MME, Ministério de Minas e Energia. Diagnóstico do município de Coronel João Pessoa. Recife: CPRM, 2005.

NELSON, R. A. R. R.. Da importância dos recursos hídricos e a organização administrativa para sua proteção. Planeta Amazônia: Revista Internacional do Direito Ambiental e Políticas Públicas, v.1, n.9, p.71-88, 2017. DOI: https://doi.org/10.18468/planetaamazonia.2017n9.p71-88

NERY, T. D.. O uso de parâmetros morfométricos na avaliação do potencial a geração de corridas de detritos na bacia do Rio Santo Antônio. Revista Brasileira de Cartografia, v.68, n.9, 2016

PEREIRA, J. A. V.; SILVA, J. B.; DUARTE, S. M. A.. Análise Ambiental da Bacia de Drenagem do Açude Mucutú/PB Utilizando Sensoriamento Remoto. Revista Brasileira de Geografia Física, v.12, n.3, p.1017-1038, 2019. DOI: https://doi.org/10.26848/rbgf.v12.3.p1017-1038

PEREIRA, M. D. R.; CRISTO, S. S. V.. Análise da susceptibilidade a inundação na bacia hidrográfica do córrego São João, Porto Nacional - TO. Interface, v.16, n.16, p.82-96, 2018

PEREIRA, T. R. B.; VITAL, H.; SILVA, A. G. A.; OLIVEIRA, C. A.. Comparison of automatic and semi-automatic methods for classification of side scan sonar imagery. Brazilian Journal of Geophysics, v.37, n.1, p.1-10, 2019. DOI: http://dx.doi.org/10.22564/rbgf.v37i1.1985

RODRIGUES, V. A.; CARDOSO, L. G.; POLLO, R. A. Caracterização Morfológica de Microbacia na Cuesta de Botucatu - São Paulo - Brasil. Irriga. Botucatu, v.1, n.1, p.211-220, 2015. DOI: https://doi.org/10.15809/irriga.2015v1n1p211

ROMEIRO, A. C. C.. Mapeamento do uso e ocupação do solo da microbacia hidrográfica do Ribeirão ForquilhaGoianésia-GO. Monografia (Bacharelado em Agronomia) Faculdade Evangélica de Goianésia, Goianésia, 2018.

SANTANA, D. B.; MOREIRA, R. S.; PARREIRAS, T. C.; SILVA, L. F. P. M.; TEODORO, A. E. M.; BOLELLI, T. M.; LENSE, G. H. E.; MINCATO, R. L.. Adoção de multicritérios para análise da suscetibilidade erosiva em sub-bacias hidrográficas da Serra da Mantiqueira, sul de Minas Gerais. Caderno De Ciências Agrárias, v.11, n.1, p.1-9, 2019. DOI: https://doi.org/10.35699/2447-6218.2019.15928

SANTOS, H. G.; JACOMINE, P. K. T.; ANJOS, L. H. C.; OLIVEIRA, V. A.; LUMBRERAR, F. J.; COELHO, M. R.; ALMEIDA, A. J.; FILHO, J. C. A.; OLIVEIRA, B. J.; CUNHA, T. J. F.. Sistema Brasileiro de Classificação de Solos. 5 ed. Embrapa: Brasília, 
2018.

SANTOS, M. A.; CARVALHO, S. M.; ANTONELI, V.. Suscetibilidade de enchentes a partir da análise das variáveis morfométricas na bacia hidrográfica rio bonito em Irati-PRbrasil. Revista Equador, v.5, n.5, p.152-167, 2016.

SANTOS, M. R. S.; MOREIRA, A. M.; SANTOS, M.. Análise socioambiental dos moradores da APP urbano do rio Cereja, Bragança/PA. In: SEMINÁRIO NACIONAL SOBRE TRATAMENTO DE ÁREAS DE PRESERVAÇÃO PERMANENTE EM MEIO URBANO, 3; E RESTRIÇÕES AMBIENTAIS AO PARCELAMENTO DO SOLO-APP URBANA, 12. Anais. Belém: UFPA, 2014

SCHUMM, S. A.. Sinuosity of alluvial rivers on the great plains. Geological Society of America Bulletin, v.74, n.9, p.1089-1100, 1963.

SILVA, B. F.; SANTOS, K. A.. Análise físico-funcional da bacia hidrográfica do córrego Samambaia/GO. Revista Geográfica Acadêmica, v.10, n.1, p.44-55, 2016.

SILVA, W. B.; BEZERRA, J. M.; FEITOSA, A. P.; SILVA, P. C. M.; REGO, A. T.. Uso e Ocupação do Solo na Bacia Hidrográfica do Açude Santa Cruz do Apodi - RN. Anuário do Instituto de Geociências, Rio de Janeiro, v.43, n.1, p.397-407, 2020a. DOI: https://doi.org/10.11137/20201397407

SILVA, R. M.; HENRIQUES, I. G. N.; CAZÉ, J. F.. Simulação das mudanças de uso e ocupação do solo e seus efeitos nas características hidrossedimentológicas em uma bacia do bioma caatinga. Revista de Geografia, Recife, v.35, n.1, p.158-179, 2018.

SILVA, V. F.; PEREIRA, J. S.; COSME, A. M. F.; PESSOA, D. S.;
MARTINS, W. A.; LIMA, V. L. A.; DANTAS NETO, J.. Análise da degradação da vegetação nativa em área de preservação permanente na Paraíba. Revista Brasileira de Geografia Física, v. 13, p.121-131, 2020. DOI: http://dx.doi.org/10.26848/rbgf.v13.1.p121-130

SOARES, T. R.. Planejar a terra para preservar a água: a legislação e o planejamento do uso e ocupação do solo na sub-bacia Juqueri-Cantareira e as interfaces entre as políticas urbana, regional e de recursos hídricos. Dissertação (Mestrado em Arquitetura, Tecnologiae Cidade) Universidade Estadual de Campinas, Campinas, 2018.

SOUZA, L. A.; SOBREIRA, F. G.. Proposta de unidades geomorfológicas como suporte à expansão urbana e ao ordenamento territorial. Revista Brasileira de Geomorfologia, v.18, n.4, 2017. DOI: http://dx.doi.org/10.20502/rbg.v18i4.1235

SPETH, G.; PERES, L. E. S.; WOLLMANN, L.; DOMINGUES, Q. R.; GIACCOM-RIBEIRO, B. M.. Land use conflicts in permanent preservation areas in Candelária (RS, Brazil). Ciência e Natura, v.42, n.13, 2019. DOI: https://doi.org/10.5902/2179460X40485

STRAHLER, A. N.. Quantitative analysis of watershed geomorphology. American Geophysical Union, v.38, n.1, p.913-920, 1957. DOI: https://doi.org/10.1029/TR038i006p00913

VALE, J. R. B.; BORDALO, C. A. L.; FONSECA, L. C. M.. Análise do uso e cobertura da terra na Bacia Hidrográfica do rio Apeú, Nordeste Paraense, entre os anos de 1999 e 2014. Revista do Instituto Histórico e Geográfico do Pará, Belém, v.2, n.2, p.76-83, 2015. DOI: http://dx.doi.org/10.17553/2359-0831/ihgp.v2n2p76-83

A CBPC - Companhia Brasileira de Produção Científica (CNPJ: 11.221.422/0001-03) detém os direitos materiais desta publicação. Os direitos referem-se à publicação do trabalho em qualquer parte do mundo, incluindo os direitos às renovações, expansões e disseminações da contribuição, bem como outros direitos subsidiários. Todos os trabalhos publicados eletronicamente poderão posteriormente ser publicados em coletâneas impressas sob coordenação da Sustenere Publishing, da Companhia Brasileira de Produção Científica e seus parceiros autorizados. Os (as) autores (as) preservam os direitos autorais, mas não têm permissão para a publicação da contribuição em outro meio, impresso ou digital, em português ou em tradução. 